Special issue of the International Conference on Computational and Experimental Science and Engineering (ICCESEN 2014)

\title{
Thermodynamic Study: C-H Bond Activation of Methane with $\mathrm{OsO}^{+}$
}

\author{
F. Aynali ${ }^{a, *}$ And G.A. Altun Ciftcioglu ${ }^{b}$ \\ ${ }^{a}$ Gebze Institute of Technology, Department of Chemical Engineering, Kocaeli, Turkey \\ ${ }^{b}$ Marmara University, Department of Chemical Engineering, İstanbul, Turkey
}

\begin{abstract}
Catalysis plays a critical role in the accomplishment of industrially significant chemical transformations, by requiring less energy investment in underlying processes. Computational chemistry has had a pronounced impact on the understanding of the role of catalysts at the atomic and molecular level, contributing to design of more efficient catalysts. In this study, we compute thermochemical properties attending $\mathrm{C}-\mathrm{H}$ bond activation of methane by $\mathrm{OsO}^{+}$and enabling subsequent dehydrogenation and dehydration reactions. It is found that the dehydrogenation channel is thermodynamically more favorable. This study should contribute to the understanding of $\mathrm{C}-\mathrm{H}$ bond activation using homogeneous catalysis of partial oxidation of natural gas (methane) leading to formation of the easily transported liquid fuel methanol.
\end{abstract}

DOI: 10.12693/APhysPolA.128.B-167

PACS: 03.65.--w, 31.15.Ew

\section{Introduction}

Methane is the main constituent of natural gas. Natural gas is a valuable energy source and a potential feedstock for the production of fuels and other useful chemicals [1]. Unfortunately, transport of this highly volatile and extremely flammable gas is inconvenient and hazardous.

To make methane reactive at least one of its $\mathrm{C}-\mathrm{H}$ bonds must be activated. The key is to find an efficient way to do this under ambient conditions. The use of transition metal catalysts can help to minimize both the energy demand and the environmental impact of the conversion process. There has been considerable experimental and theoretical interest on the catalytic functionalization of $\mathrm{C}-\mathrm{H}$ bonds of small hydrocarbons by organometallic mechanisms involving particularly electron rich late transition metal oxide cations [2-6]. Thus, in this study, $\mathrm{OsO}^{+}$mediated dehydrogenation of methane, a key early step in the production of methanol, is investigated using computational quantum chemistry, to contribute to the understanding of $\mathrm{C}-\mathrm{H}$ bond activation using homogeneous catalysis.

\section{Computational methods}

We employed GAUSSIAN software [4] for structural and energetic calculations. We optimized all the structures in the mechanism for OsO cation's reaction with methane described below (reactions (1)-(4)) with the B3LYP functional and the $6-311 \mathrm{G}^{* *}$ basis for all the atoms except Os for doublet and quartet spin states. The LANL2DZ basis is used for the heavy metal atom.

*corresponding author; e-mail: faynali@gyte.edu.tr

\section{Reaction mechanism}

The main reaction steps considered in this work for the $\mathrm{C}-\mathrm{H}$ bond activation resulting in the dehydrogenation of methane by a gas-phase $\mathrm{OsO}^{+}$are listed below

$$
\begin{aligned}
& \mathrm{OsO}^{+}+\mathrm{CH}_{4} \rightarrow \mathrm{OOs}\left(\mathrm{CH}_{4}\right)^{+}, \\
& \mathrm{OOs}\left(\mathrm{CH}_{4}\right)^{+} \rightarrow\left[\mathrm{OOs} \cdots \mathrm{H} \cdots\left(\mathrm{CH}_{3}\right)^{+}\right] * \rightarrow \\
& \mathrm{OOsH}\left(\mathrm{CH}_{3}\right)^{+}, \\
& \mathrm{OOsH}\left(\mathrm{CH}_{3}\right)^{+} \rightarrow\left[\mathrm{OOs} \cdots \mathrm{H}_{2} \cdots\left(\mathrm{CH}_{2}\right)^{+}\right]^{*} \rightarrow \\
& \quad \mathrm{OOs}\left(\mathrm{H}_{2}\right)\left(\mathrm{CH}_{2}\right)^{+}, \\
& \mathrm{OOs}\left(\mathrm{H}_{2}\right)\left(\mathrm{CH}_{2}\right)^{+} \rightarrow\left[\mathrm{H}_{2} \cdots \mathrm{OsO}\left(\mathrm{CH}_{2}\right)^{+}\right] \rightarrow \\
& \mathrm{OsO}\left(\mathrm{CH}_{2}\right)^{+}+\mathrm{H}_{2} .
\end{aligned}
$$

\section{Potential energy surface calculations}

The reaction steps (1)-(4) are simulated using Gaussian 09 software [7]. Multiplicities are assumed to be doublet for all the species involved in reactions (1) through (4) except for the species $\mathrm{OsO}^{+}$and $\mathrm{OsO}\left(\mathrm{CH}_{2}\right)^{+}$ occurring in reaction steps (1) and (4), respectively. These two species are assumed to go through spin flip transitions and acquire quartet multiplicities. Os is a heavy atom and the spin state is not well defined owing to extensive spin-orbit coupling, so we follow the lower energy state regardless of spin to define the reaction paths. Metal oxide cations react more efficiently with methane in their high-spin states than in lowspin states [3]. However, the complex generated in reaction (1), $\mathrm{OOs}\left(\mathrm{CH}_{4}\right)^{+}$, is more stable with the doublet spin multiplicity. The complexation reaction (1) is exothermic with $H=-23.0 \mathrm{kcal} \mathrm{mol}^{-1}$. Thus, as shown in Fig. 1 the complex can rearrange to form OOsH $\left(\mathrm{CH}_{3}\right)^{+}$cation ${ }^{2} 3$, through the oxidative addition step (2) by passing through an extremely shallow transition state indicated by $\left[\mathrm{OO} \cdots \mathrm{H} \cdots\left(\mathrm{CH}_{3}\right)^{+}\right]^{*}$ 
and labelled as $2 \mathrm{TS} 2 / 3$. The reaction leading to the $\mathrm{OOsH}\left(\mathrm{CH}_{3}\right)^{+}$cation doublet ${ }^{2} 3$ is endothermic by $4.064 \mathrm{kcal} \mathrm{mol}^{-1}$ relative to ${ }^{2} 2$. This result disagrees with the calculation presented by Zhang et al. [8] who predict that reaction (2) should be exothermic by $-24.0 \mathrm{kcal} \mathrm{mol}^{-1}$. The species ${ }^{2} 3$ goes over a transition state enthalpy barrier of $4.972 \mathrm{kcal} \mathrm{mol}^{-1}$ to produce the complex ${ }^{2} 4$. However, the overall reaction (3) is exothermic by $-5.960 \mathrm{kcal} \mathrm{mol}^{-1}$. In reaction step (4), a reductive elimination, the species ${ }^{2} 4$ is then assumed to release $\mathrm{H}_{2}$ and the remaining cation flips its spin back to quartet. The production of $\mathrm{H}_{2}$ gas from methane using $\mathrm{OsO}^{+}$catalyst is exothermic with an overall enthalpy change of $-10.859 \mathrm{kcal} \mathrm{mol}^{-1}$.

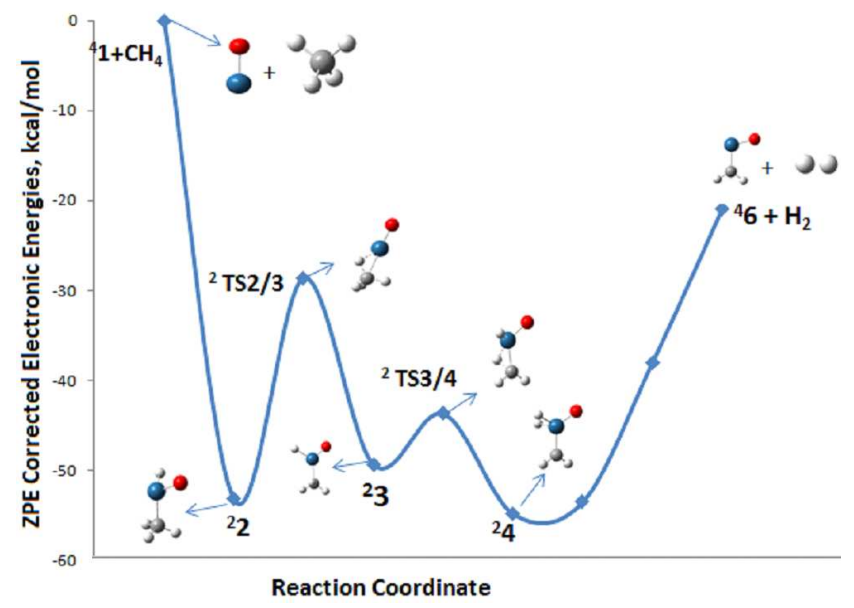

Fig. 1. PES for the dehydrogenation reaction (changes in spin state are shown).

Although the PES of the dehydration channels and reaction mechanism are not shown here, it is calculated to compare with the dehydrogenation reaction process (Fig. 1). The comparison clearly showed that the reaction steps leading to $\mathrm{H}_{2}$ production is more favorable by $8.43 \mathrm{kcal} / \mathrm{mol}$ than the reactions leading to $\mathrm{H}_{2} \mathrm{O}$ production.

\section{Calculation of thermodynamic properties}

We conducted calculations of thermodynamic parameters for the dehydrogenation process, for which experimental information is available for comparison [9]:

$$
{ }^{4} \mathrm{OsO}^{+}+\mathrm{CH}_{4} \leftrightarrow{ }^{4} \mathrm{OsO}\left(\mathrm{CH}_{2}\right)+\mathrm{H}_{2} \text {. }
$$

In these calculations a method based on atomization energies was used to obtain the $\Delta G_{\text {formation of }}$ enthalpy and $\Delta H_{\text {formation }}$ [10]. This method requires both theoretical and experimental values for the formation energies of the individual atoms in every species. In applying this formula the heats of formation of atomic carbon, hydrogen, oxygen, and osmium are taken from the experiments (JANAF tables). The values taken from the JANAF tables are: $\Delta H_{f, 298.15 \mathrm{~K}}^{\mathrm{o}}(\mathrm{C})=$ $171.21 \mathrm{kcal} \mathrm{mol}^{-1}, \Delta H_{f, 298.15 \mathrm{~K}}^{\mathrm{o}}(\mathrm{H})=52.10 \mathrm{kcal} \mathrm{mol}^{-1}$,
$\Delta H_{f, 298.15 \mathrm{~K}}^{\mathrm{o}}(\mathrm{O})=59.43 \mathrm{kcal} \mathrm{mol}^{-1}, \Delta H_{f, 298.15 \mathrm{~K}}^{\mathrm{o}}(\mathrm{Os})=$ $189.18 \mathrm{kcal} \mathrm{mol}^{-1}$. For a molecule of the general structural formula $\mathrm{C}_{a} \mathrm{H}_{b} \mathrm{O}_{c} \mathrm{Os}_{d}, \Delta H_{\text {formation }}$ is defined by the following expression:

$$
\begin{aligned}
& \Delta H_{f, 298.15 \mathrm{~K}}^{\mathrm{o}}\left(\mathrm{C}_{a} \mathrm{H}_{b} \mathrm{O}_{c} \mathrm{Os}_{d}\right)=\left[a \Delta H_{f, 298.15 \mathrm{~K}}^{\mathrm{o}}(\mathrm{C})\right. \\
& +b \Delta H_{f, 298.15 \mathrm{~K}}^{\mathrm{o}}(\mathrm{H})+c \Delta H_{f, 298.15 \mathrm{~K}}^{\mathrm{o}}(\mathrm{O}) \\
& \left.+d \Delta H_{f, 298.15 \mathrm{~K}}^{\mathrm{o}}(\mathrm{Os})\right]-\left[a H^{298.15}(\mathrm{C})\right. \\
& +b H^{298.15}(\mathrm{H})+c H^{298.15}(\mathrm{O})+d H^{298.15}(\mathrm{Os}) \\
& \left.+\left(\mathrm{C}_{a} \mathrm{H}_{b} \mathrm{O}_{c} \mathrm{Os}_{d}\right)\right] .
\end{aligned}
$$

The enthalpies for the atoms $\mathrm{C}, \mathrm{H}, \mathrm{O}$, and Os and enthalpies for all the molecular species involved in the reaction were calculated using Gaussian 09. The mathematical expression used in the calculations of enthalpies from Gaussian 09 is given below

$$
\begin{aligned}
& H^{298.15}=E_{\mathrm{e}}+Z P E+E_{\mathrm{v}}^{298.15}+E_{\mathrm{tr}}^{298.15} \\
& \quad+E_{\mathrm{r}}^{298.15}+\Delta P V,
\end{aligned}
$$

where $E_{\mathrm{e}}$ represents the electronic energy, $Z P E$ is the zero point vibrational energy contribution, $E_{\mathrm{v}}, E_{\mathrm{r}}$, and $E_{\mathrm{tr}}$ are the vibrational, the rotational, and translational energies rescpectively. $\triangle P V$ is set to be RT in the actual calculation. An analogous equation defines the Gibbs energies. Computed energies for the individual atoms are listed in Table I. Calculated enthalpies and Gibbs free energies of formation are listed in Tables II and III. The thermodynamic changes calculated by Eq. (6) are listed in Table IV.

\section{TABLE I}

Total electronic energies.

\begin{tabular}{c|c|c}
\hline \hline & \multicolumn{2}{c}{ B3LYP $/ 6-311 \mathrm{G}(\mathrm{d}, \mathrm{p})$} \\
\hline & $\begin{array}{c}\text { Enthalpy } \\
{[\mathrm{kcal} / \mathrm{mol}]}\end{array}$ & $\begin{array}{c}\text { Gibbs } \\
{[\mathrm{kcal} / \mathrm{mol}]}\end{array}$ \\
\hline $\mathrm{O}$ & -17.9292 & -17.9331 \\
Os & -21.4309 & -21.436 \\
$\mathrm{H}$ & -313.927 & -322.101 \\
$\mathrm{C}$ & -23762.6 & -23773.2
\end{tabular}

\section{TABLE II}

The calculated formation of enthalpy and the Gibbs energies for the reactants and products for the quartet quantum state.

\begin{tabular}{c|c|c}
\hline \hline \multicolumn{3}{c}{ B3LYP $/ 6-311 \mathrm{G}(\mathrm{d}, \mathrm{p})$} \\
\hline & $\begin{array}{c}\text { Enthalpy } \\
{[\mathrm{kcal} / \mathrm{mol}]}\end{array}$ & $\begin{array}{c}\text { Gibbs } \\
{[\mathrm{kcal} / \mathrm{mol}]}\end{array}$ \\
\hline $\mathrm{OsO}$ & -576.307 & -585.5194 \\
$\mathrm{CH}_{4}$ & -20.5361 & -16.80493 \\
$\mathrm{H}_{2}$ & 0.26106 & 0.2729353 \\
$\mathrm{OsCH}_{2}$ & -611.667 & -615.5766
\end{tabular}

The reaction enthalpy change seen in Table IV, which is $-14.5634 \mathrm{kcal} \mathrm{mol}^{-1}$, is very close to the 


\section{TABLE III}

The calculated formation of enthalpy and the Gibbs free energies for the reactants and products for the doublet quantum state.

\begin{tabular}{c|c|c}
\hline \hline \multicolumn{3}{c}{ B3LYP/6-311G(d,p) } \\
\hline Species & $\begin{array}{c}\text { Enthalpy } \\
{[\mathrm{kcal} / \mathrm{mol}]}\end{array}$ & $\begin{array}{c}\text { Gibbs } \\
\mathrm{kcal} / \mathrm{mol}\end{array}$ \\
\hline $\mathrm{OsO}$ & -477.86 & -486.83 \\
$\mathrm{CH}_{4}$ & -20.54 & -16.80 \\
$\mathrm{H}_{2}$ & 0.26 & 0.27 \\
$\mathrm{OsCH}_{2}$ & -608.12 & -611.60
\end{tabular}

TABLE IV

The thermodynamical property changes in the dehydrogenation reaction.

\begin{tabular}{c|l|c}
\hline \hline & Enthalpy & Gibbs free \\
\cline { 2 - 3 } & \multicolumn{2}{|c}{ change of reaction $[\mathrm{kcal} / \mathrm{mol}]$} \\
\hline doublet & -109.468 & -107.69 \\
quartet & -14.5634 & -12.9793
\end{tabular}

enthalpy change found for the reaction mechanism in quartet quantum state of dehydrogenation, which is $-10.859 \mathrm{kcal} \mathrm{mol}^{-1}$, by the B3LYP method used to calculate the PES.

\section{Conclusion}

The most important goal of this study was to investigate potential use of catalyst in order to activate methane. The proposed reaction paths found to be thermodynamically reasonable. The methane dehydrogenation by $\mathrm{OsO}^{+}$is downhill in energy on both quartet and doublet surfaces. The overall reaction considered in spin flip is exothermic by $-10.859 \mathrm{kcal} / \mathrm{mol}$. For the reaction of $\mathrm{OsO}^{+}$with methane, the dehydrogenation channel is found to be thermodynamically more preferred.

\section{References}

[1] U.S. Energy Information Administration, Annual Energy Outlook 2013, DOE/EIA-0383 (2013).

[2] J.A. Labinger, J.E. Bercaw, Nature 417, 502 (2002).

[3] B.M. Ricardo, Int. Rev. Phys. Chem. 23, 79 (2004).

[4] H. Schwarz, D. Schröder, Pure Appl. Chem. 72, 2319 (2000).

[5] P.W.N.M. Leeuwen, Homogeneous Catalysis: Understanding the Art, Kluwer Academic, Amsterdam 2004, p. 1.

[6] P.W.N.M. Leeuwen, J.A. Moulijin, R.A. Santen, Catalysis: An Integrated Approach to Homogeneous, Hetetregeneous and Industrial Catalysis, Studies in Surface Science and Catalysis, Vol. 79, Elsevier, Amsterdam 1993, p. 3.

[7] M.J. Frisch, G.W. Trucks, B. Schlegel, G.E. Scuseria, M.A. Robb, J.R. Cheeseman, G. Scalmani, V. Barone, B. Mennucci, G.A. Petersson, H. Nakatsuji, M. Caricato, X. Li, H.P. Hratchian, A.F. Izmaylov, J. Bloino, G. Zheng, J.L. Sonnenberg, M. Hada, M. Ehara, K. Toyota, R. Fukuda, J. Hasegawa, M. Ishida, T. Nakajima, Y. Honda, O. Kitao, H. Nakai, T. Vreven, J.A. Montgomery, Jr., J.E. Peralta, F. Ogliaro, M. Bearpark, J.J. Heyd, E. Brothers, K.N. Kudin, V.N. Staroverov, R. Kobayashi, J. Normand, K. Raghavachari, A. Rendell, J.C. Burant, S.S. Iyengar, J. Tomasi, M. Cossi, N. Rega, J.M. Millam, M. Klene, J.E. Knox, J.B. Cross, V. Bakken, C. Adamo, J. Jaramillo, R. Gomperts, R.E. Stratmann, O. Yazyev, A.J. Austin, R. Cammi, C. Pomelli, J.W. Ochterski, R.L. Martin, K. Morokuma, V.G. Zakrzewski, G.A. Voth, P. Salvador, J.J. Dannenberg, S. Dapprich, A.D. Daniels, O. Farkas, J.B. Foresman, J.V. Ortiz, J. Cioslowski, D.J. Fox, Gaussian 09, Revision A.2, Gaussian Inc., Wallingford, CT 2009.

[8] G. Zhang, S. Li, Y. Jiang, Organometallics 23, 3656 (2004).

[9] H. Schwarz, D. Schröder, PNAS 105, 18114 (2008).

[10] S.S. Khan, X. Yu, J.R. Wade, R.D. Malmgren, L.J. Broadbelt, J. Phys. Chem. A 113, 5176 (2009). 